University of Nebraska - Lincoln

DigitalCommons@University of Nebraska - Lincoln

Faculty Publications, Department of Child, Youth, and Family Studies

Child, Youth, and Family Studies, Department of

$9-1-2005$

\title{
Prosocial behaviors in context: A study of the Gikuyu children of Ngecha, Kenya
}

\author{
Maria Rosario de Guzman \\ University of Nebraska-Lincoln, mguzman2@unl.edu \\ Carolyn P. Edwards \\ University of Nebraska-Lincoln, cedwards1@unl.edu \\ Gustavo Carlo \\ University of Nebraska-Lincoln
}

Follow this and additional works at: https://digitalcommons.unl.edu/famconfacpub

Part of the Family, Life Course, and Society Commons

de Guzman, Maria Rosario; Edwards, Carolyn P.; and Carlo, Gustavo, "Prosocial behaviors in context: A study of the Gikuyu children of Ngecha, Kenya" (2005). Faculty Publications, Department of Child, Youth, and Family Studies. 3.

https://digitalcommons.unl.edu/famconfacpub/3

This Article is brought to you for free and open access by the Child, Youth, and Family Studies, Department of at DigitalCommons@University of Nebraska - Lincoln. It has been accepted for inclusion in Faculty Publications, Department of Child, Youth, and Family Studies by an authorized administrator of DigitalCommons@University of Nebraska - Lincoln. 


\section{Prosocial behaviors in context: A study of the Gikuyu children of Ngecha, Kenya*}

\author{
Maria Rosario T. de Guzman \\ Carolyn Pope Edwards \\ Gustavo Carlo \\ University of Nebraska-Lincoln
}

\begin{abstract}
This study examines children's prosocial behaviors in everyday contexts that represent varying degrees of strength of situational demands. Behavioral observations of children $(\mathrm{N}=89)$ ages 2 to 10 years $(M=5.25, S D=2.23)$., collected in Ngecha, Kenya were coded for 3 types of prosocial behaviors (nurturant, responsible and prosocial dominant) and the contexts in which these behaviors emerged (childcare, self care, labor/chores, play, idle/ social). Mixed factorial ANOVAs showed age differences in prosocial behaviors favoring older children as well as context effects. Prosocial behaviors occurred more frequently than in labor/chores than in play, idle/social or self-care contexts; and prosocial behaviors occurred more frequently during play and idle/social contexts than in self-care contexts. Most nurturant behaviors were performed during childcare. Most responsible behaviors were performed during labor/chores. The contextual differences for responsible and nurturant behaviors were found mostly for the older age groups. Lastly, older children exhib-
\end{abstract}

* Published in Journal of Applied Developmental Psychology 26 (2005), pp. 542-558 Copyright (c) 2005 Elsevier Inc. All rights reserved.

http://www.sciencedirect.com/science/journal/01933973 ited prosocial dominant behaviors more often than did younger children. Results suggest that both individual level and contextual variables are important in studying different types of prosocial behaviors. Implications for parents and educators are discussed.

\section{Introduction}

Prosocial behaviors (i.e., behaviors intended to benefit others; Eisenberg \& Fabes, 1998) and their development in children are issues that have drawn increased interest in recent years. Many researchers have investigated various facets of these positive behaviors, including their developmental and socialization underpinnings, and both personal and social context variables to predict individual differences (for reviews, see Batson, 1998 and Eisenberg \& Fabes, 1998). However, although psychological studies have clearly documented social-personality differences that predict individual differences in prosocial behaviors and development (e.g., Carlo, Knight, Eisenberg, \& Rotenberg, 1991), fewer studies highlight the influence of situational or social context variables. The present study was designed to examine children's prosocial behaviors across their everyday settings, representing varying degrees of "weak" and "strong" contexts.

Snyder and Ickes (1985) proposed one manner by which dispositions and contexts work together to influence behavior. They suggested that the manifestation of individual variability depends in large part on the strength of situational variables. That is, given a particular category of individuals, some situational variables are "strong" or potent in their eliciting power and tend to limit or constrain the range of behaviors that individuals exhibit, thus muting individual variability. In contrast, other situational variables are "weak" in their eliciting power 
and tend to have minimal influence on behaviors, thus amplifying the expression of individual variability.

The potential of contexts to elicit or inhibit particular behaviors is likewise recognized by cultural psychologists and anthropologists who propose socialization models that focus on what they variously refer to as the "learning environment" (Whiting, 1980), “activity settings" (Farver, 1999; Tudge et al.,1999; Weisner, 2002), or the "developmental niche" (Super \& Harkness, 1986, 1999). These researchers agree in emphasizing the importance of routine, everyday settings in shaping children's behavior, learning, and development and setting the course for particular developmental outcomes.

Following Whiting (1980), we operationally defined the child's context as "characterized by an activity in progress, a physically defined space, a characteristic group of people, and norms of behavior" (p. 7). Anthropologists and psychologists have presented strong evidence of how children's lives vary worldwide in their routine activities, settings, and social companions in ways relevant to prosocial development, and consistent with parental belief systems and child characteristics (Bloch \& Adler, 1994; Larson \& Verma, 1999; Munroe, Munroe, \& Shimmin, 1984; Munroe \& Munroe, 1977; Rogoff, Newcombe, Fox, \& Ellis, 1980; Rogoff, Sellers, Pirrotta, Fox, \& White, 1975; Weisner \& Gallimore, 1977; Whiting \& Edwards, 1988; Whiting \& Whiting, 1975).

Moreover, the regularities within the settings organize children's developmental experiences and provide the information from which children construct the rules of their culture (Super \& Harkness, 1986). The context of child work, for instance, can be considered an essential component of child training, "the core process by which children learn roles and skills" (Nsamenang, 1992, p. 156). For example, Grusec, Good- now, and Cohen (1997) found that American children who performed household tasks benefiting others were also more likely to spontaneously exhibit concern for others.

The strongest evidence may exist for socialization to nurturance through frequent interaction with infants and toddlers (Edwards, 1993). American children's interest in infants has been studied by a number of investigators with an emphasis on children's responses to unfamiliar infants, outside of a family context (Fogel \& Melson, 1986). Berman and associates (Berman \& Goodman, 1984; Reid, Tate, \& Berman, 1989) found that during both early and middle childhood boys and girls approach and respond positively to unfamiliar infants and toddlers. Sex differences in attraction to infants are not clearly evident before age 5 , at which time boys tend to become watchful and protective but generally passive toward babies unless they need direct instrumental help, whereas girls become highly interactive and nurturant.

Furthermore, in other societies such as among Kenyan children, girls are consciously and explicitly socialized by mothers for future maternal roles through task assignment. In such subsistence-based societies where busy mothers recruit help from older children, children under age 5 to 6 years are not usually considered mature enough to be consistent and reliable as infant nurses, but starting in middle childhood, girls are the preferred child nurses and are assigned to settings with infants and toddlers. However, boys too can be drawn in, and gender differences are weaker in societies with less gender differentiation of roles. Overall, gender differences in infant/toddler contact, interaction, and nurturance appear around age 5 and remain or increase over middle childhood (Edwards, 1993).

The naturalistic, cross-cultural data thus suggest that everyday contexts of socialization may interact with personal vari- 
ables such as age, gender, and kinship relationship-factors studied by developmental psychologists in more tightly controlled studies of prosocial behavior. The findings of these studies are somewhat equivocal with respect to age and gender. With increasing age, children in contemporary industrialized societies sometimes show more prosocial behavior and/or improved complexity in prosocial responding, likely due to improvements in their cognitive abilities, socio-emotional skills, and the physical ability to carry out behaviors (for reviews, Eisenberg \& Fabes, 1998; Zahn-Waxler, Friedman, \& Cummings, 1983). However, other studies have found either no or inconsistent age effects (Lloyd \& Smith, 1986; Radke-Yarrow, Zahn-Waxler, \& Chapman, 1983). Findings on gender differences are even more mixed, though those significant differences that are found do favor girls (see meta-analytic section of Eisenberg \& Fabes, 1998).

The present study was conducted with Gikuyu children in the village of Ngecha, Kenya during the years 1968 through 1972. The observations were collected as part of a long-term, multi-site, and interdisciplinary research project called the Child Development Research Unit, based at Nairobi University in Kenya. Findings based on this data set were reported by Cox (1977), (Edwards and Whiting, 1980, 1993), Leiderman and Leiderman (1977), Wenger (1976),Whiting and Edwards (1988) and Worthman and Whiting (1987). The entire corpus of Ngecha observations has recently been made available to the wider research community (Whiting, 2003). Such archival data sets represent valuable resources in social science that, if carefully preserved, can be reanalyzed asking new questions or using updated interpretive and/or statistical analytic techniques. For example, the Kisa-Kariobangi observations have been mined for their lessons about family adaptation to chil- dren's cognitive transition at age 5-7 (Weisner, 1996), the Ngecha mother interviews and observations data for insight into the historical role of East African women as agents of social change (Edwards \& Whiting, 2004), the Kenya infant spot observations for an understanding of the cultural management of infant states of sleep and arousal (Super, 1990), and the Six Culture child observations for information about play in contexts where children had little contact with commercial toys or the waste products of the industrial world from which to fashion play objects (Edwards, 2000).

Given the importance of archival data for research on childhood across time and space, the Human Relations Area Files in New Haven, Connecticut, is today systematically publishing archival data sets based on quantitative methodologies, while the Smithsonian Institution in Washington, D.C. is a repository of ethnographic film. The Ngecha observations were collected under the leadership of Beatrice Whiting following rigorous scientific standards (Whiting, 2003; Whiting \& Edwards, 1988; Whiting et al., 1966); and though the training of observers involved no method of obtaining electronic records (video or audio), nevertheless the observation process would not seem to be systematically biased with respect to aspects of prosocial behavior.

Because the Ngecha data set is large and covers the full age range from infancy through middle childhood, the observations allow for a differentiated look at prosocial behaviors, as distinct types may be motivated or predicted by divergent correlates (Carlo \& Randall, 2001). The data set also contains enough social acts to allow for statistical analysis of several kinds of prosocial behaviors as a function of age, gender, and strength characteristics of the context. The analysis can separate the statistical effects of context from those of age and gender, 
and focus on age variations in a more specific way than was possible in earlier studies (e.g., Whiting \& Edwards, 1973; Whiting \& Whiting, 1971), which used broad age categories of 3-6 versus 7-10 year olds (Whiting \& Edwards, 1988, aggregated data of individuals within sex-age categories, because numbers of social acts per individual were often small).

Furthermore, because the Ngecha children were observed naturalistically in home, yard, and neighborhood settings, the findings may contribute information about ecological validity. Various scholars have acknowledged the need to extend research in prosocial literature to a wider range of societal samples (Carlo, Fabes, Laible \& Kupanoff, 1999; Miller, Kozou, \& Davis, 2001; Tietjen, 1986; Whiting, 1983). Eisenberg and Fabes (1998) noted that systematic observations of prosocial behaviors in non-Western, non-industrialized societies are scarce, limiting conclusions that can be made.

Finally, the Gikuyu children in the village of Ngecha accessed contexts somewhat differently than did those living in complex industrial economies. Munroe et al. (1982) have identified the range of contexts in which many Gikuyu children can usually be found. At the time of the research study, Ngecha children participated in contexts appropriate for play, leisure, and several kinds of subsistence work (e.g., sibling care, animal care, garden labor, food production, transportation of fuel and water; Edwards \& Whiting, 2004). The Gikuyu children thus participated in a set of contexts with a full range of prosocial eliciting power from strength to weakness, in contrast to what might be expected for children whose typical contexts (school activities and peer play) are relatively weak in prosocial elicitation.

While the limited related literature makes it difficult to draw firm conclusions, some hypotheses can be made about which contexts are particularly conducive to specific types of prosocial behaviors. The childcare context can be considered a particularly strong situation in eliciting nurturant prosocial acts (i.e., behaviors intended to meet the needs of others). The presence and the tending of an infant elicit nurturing styles of prosocial behavior because of the relative helplessness and dependency of the small infant and his/ her cute and endearing physical characteristics (Braten, 1996; Edwards, 1986, 1993; Hay \& Rheingold, 1983; Whiting \& Edwards, 1988). In fact, research has shown that infant crying is a strong stimulus that elicits empathic emotional responding as well as prosocial behaviors among children, even those very young in age (Radke-Yarrow et al., 1983). Munroe et al. (1984) have also established significant correlations between levels of infant caregiving and nurturance scores for both boys and girls even when not engaged in caregiving. In contrast, caring for toddlers seems to elicit less nurturance and more prosocial dominant behaviors (i.e., behaviors that attempt to change another person's behavior for their benefit) from older children because of the increased independence, mobility, and demandingness of the toddler and thus the corresponding need to limit, socialize, and keep the child safe (Whiting, 1983).

The contexts of various types of labor and chores might also be considered as particularly strong, given that the main purpose of being in these contexts is to perform and accomplish particular tasks. Especially in countries with subsistence economies, children are strongly expected to perform responsibly in this regard. In those contexts, one might expect frequent responsible prosocial behaviors (i.e., behaviors that benefit others indirectly or not immediately). Because the tasks are usually aimed at fulfilling the needs of others e.g., cleaning, animal 
tending), albeit indirectly, this context represents strong context demands to act in a prosocially responsible manner.

In addition to responsible behaviors, a high incidence of prosocial dominance might also be expected from the contexts of labor and various types of chores. Certain types of chores, including those that necessitate working with animals, can elicit dominant behaviors. Whiting and Whiting (1971), reporting on findings from a worldwide sample, found that boys assigned the responsible work of herding domestic animals showed more prosocial dominance than boys from societies where such tasks were not given. These differences emerged only at the age when the boys began the work, suggesting that the behavioral differences were linked to task assignment. Also, in societies like the Gikuyu, where various members of the family work together to accomplish tasks, children of varying ages are often placed in each others' company, potentially eliciting prosocial dominant styles of behavior from the older children if they are working alongside toddlers. Similarly, Ember (1973) showed that Luo boys in a rural community in Western Kenya who were assigned "feminine work" (including housework) were higher in prosocial dominance (including giving commands to others to do useful tasks or contribute to the group or household) than other boys.

Play is a context that might be considered moderate at best in its context demands because it varies in its goals and ongoing activities. Furthermore, a child might engage in play with or without others, and when with others, sometimes with same-or different-aged peers, or with same-or opposite-gender playmates. When the child is alone, there are fewer opportunities to be prosocial. When the child is in the context of play with other children, the strength of the context might vary depending on the characteristics of the other children. Addi- tionally, the potentially varied age gaps between members of play groups or pairs might place divergent amounts of situational demands to be prosocial. In particular, if a playmate is an infant, nurturant behaviors and dominant behaviors might be elicited, but the expectation is not that strong if the other child is of proximate age. Studies support this notion of having variable context demands during play. For example, RadkeYarrow and Zahn-Waxler (1976) found that the frequency of prosocial behaviors could vary as a function of the composition of play dyads.

In the case of the present sample, play is considered as part of the education of the Gikuyu child from which lessons of cooperation, turn-taking, control of aggression, rules of fairness and appropriate conduct, sharing, and helpfulness are learned (Kenyatta, 1966; Leacock, 1976). While play can be a weak context because it is chosen freely with minimal direction from adults, it often becomes a way by which children practice future roles and work. Additionally, children from Kenya and other African nations have been found to incorporate their work and tasks during their play, oftentimes by imitating older children, and participating in their tasks in a small capacity (Bloch \& Adler, 1994; Edwards, 2000). Thus, although play can sometimes reflect a relatively strong context, in general, play among the Gikuyu children was deemed a moderate situation because of the wide range of variability in the potential activities and playmates.

Other contexts, such as idleness and social visiting represent weak contexts as they pertain to prosocial behaviors because there are no explicit prosocial expectations associated with them. In such situations, individual variability is more likely manifested. Social visiting might occur between various combinations of individuals (e.g., same or opposite gender, 
same or different ages, two or more people) and might involve any number of activities. Even more so, idleness has no specific goals or expectations. As such, those are weak contexts under which age and gender differences in prosocial behaviors might be found.

The context of self-care is also weak in eliciting prosocial behaviors. However, it may be a strong context for eliciting self-focused behaviors as it is, after all, mainly directed at fulfilling one's needs. For example, Grusec et al. (1997) found no relations between the frequency of performing self-focused chores (e.g., fixing one's bed) and expression of concern towards others. Self-care mainly involves activities such as tending to one's hygiene, feeding one's self, and fulfilling one's needs, and thus offers few opportunities to be prosocial towards others as it is a context in which the focus is on one's self. In fact, self-care contexts can be considered a strong context for inhibiting prosocial acts because of the very selffocused nature of this setting. As such, relatively low levels of prosocial behaviors are expected, and few age and gender differences are hypothesized.

In summary, the present study was designed to examine the role of the context in the performance of prosocial behaviors in Gikuyu children's everyday natural settings. Based primarily on theory (e.g., Snyder \& Ickes, 1985), the following hypotheses were developed. First, children were expected to exhibit the highest number of total prosocial behavior in contexts "strong" in eliciting these behaviors (labor and chores, and childcare); the lowest number in "weak" contexts (idle, and social/visiting) as well as in "strong" contexts for eliciting selfmotivated behaviors (the self-care context); and a moderate number of prosocial acts in play contexts, which represents a moderate strength context for eliciting prosocial behaviors.
Second, nurturant (i.e., acts intended to fulfill the needs of others) and prosocial dominant behaviors (i.e., acts that are aimed at changing the behaviors of another for that person's benefit) were expected to be most frequent in the childcare context. And third, responsible behaviors (i.e., acts for the benefit of others but with no immediate recipient) were expected to be highest in the labor/chores context. In addition, given prior evidence of age and gender differences in prosocial behaviors, older children and girls were expected to exhibit higher levels of prosocial behaviors than younger children and boys. Finally, it should be noted that all three behaviors examined here (nurturant, responsible, and prosocial dominant) were all considered as prosocial behaviors; however, because these three vary considerably from each other, different hypotheses have been generated for each.

\section{Method}

\subsection{Sample}

The people of Ngecha belong to the Bantu tribe of Gikuyu, who comprise the biggest cluster of tribes in the country (Cagnolo, 1933; Knappert, 1987). The traditional Gikuyu culture has been described in the classic ethnographies by Kenyatta (1966) and Leakey (1977), as well as by Edwards and Whiting (2004).

The Ngecha community is a sublocation in the Central Province of Kenya, 20 miles northwest of the capital city, Nairobi. At the time of study, the town center consisted of a central market place, post office, hotel (serving as a men's gathering spot), gas station, public water pump, and assorted small shops. At one end were the bus station, chief's office, and primary school; at the other were a Protestant church and high 
school. Surrounding the town were seven country sections composed of farm homesteads-each section predominately occupied by members of one mbari, or patrilineage tracing their descent to a recognized founder. For the observational study, 42 households were selected from both town and farm sections, and all children between 2 and 10 years of age were observed. Those families in the town section lived on quarter-acre lots, but those in the surrounding farms lived on homesteads averaging 5.7 acres. The largest homesteads were headed by a polygynist man and extended to include his married sons and their families. Traditionally, each of the co-wives had her own hut. Traditional style huts were round, daub-and-wattle constructions with thatched roofs; but by 1968 many huts were built in the modern, rectangular, wooden frame style. Even those children living in single family homesteads had cousins living next door. In such a homestead, the child grew up surrounded by playmates-siblings, half-siblings, and cousins; as many as 36 people might live on the same homestead (Whiting \& Edwards, 1988).

On all Ngecha homesteads, each woman was allotted a garden in which to grow food for her husband and children. Land pressure was intense, partly due to the high fertility rate in the community. Mothers in the sample had an average of five living children. Traditionally the Gikuyu in the Ngecha area had been farmers with sheep, goats, and cattle, but by 1968 few families could make a living on their decreasing acreage. In the majority of households, fathers had some form of wage employment to supplement their farms. The workload of their wives was very heavy. The majority of women carried water from the town pump or nearby stream. Most did their cooking over open fires, using wood that they had collected and carried. They were the principal gardeners, responsible for raising maize, beans, and other vegetables for family consumption, and selling any surplus in the local market. Most women put in an average of $4 \mathrm{~h}$ of work a day in their gardens. A typical Ngecha mother's day has been described by (Whiting and Edwards 1988, pp. 99-101). The children were required to help according to their assessed capabilities.

Observers were secondary and college students from universities in Nairobi, Kenya, and were themselves Gikuyu. At the time of data collection, the population for Ngecha was approximately 6000. Based on the population census data on the area, families were chosen with specific intent to represent those who shared adjacent lands or shared yards. Efforts were also made to sample families that shared socialization practices and belief systems, and were familiar or at least knew each other's children. Further information regarding the sampling of families is provided in detail in Whiting and Edwards (1988) and Whiting et al. (1966).

For the purposes of this study, observations of 89 children (35 girls, 54 boys) were utilized. These children ranged in age from 2 to 10 years $(M=5.25, S D=2.23)$. Children were observed multiple times, with a total average time of $66.42 \mathrm{~min}$ $(S D=66.80)$ in combined observation time per child. Participants' observations were divided into three age groups -2 - to 3-year olds $(M=2.67, S D=.48), 4$ - to 6-year olds $(M=5.06, S D=$ $.85)$, and 7 - to 9-year olds $(M=7.94, S D=.85)$. These age groupings roughly correspond to toddler, preschool, and early childhood periods, with most days spent, respectively, at home, at the Ngecha Nursery School, or the Ngecha Primary School.

Children were observed individually. Their activities and interactions were recorded in running paragraphs. In choosing situations in which to observe a child, observers were 
instructed to obtain a "representative sample of the child's environment" (Whiting et al., 1966). To do this, observers were asked to observe children in various settings or times of the day, attempting to observe the child in various situations to represent their daily activities and lives. Periods of inactivity (i.e., sleep) were avoided. Attempts were made to sample times of the day when the child was active and/or interacting with others.

\subsection{Design and procedures}

The behavioral observations were coded for the frequency of performing three types of prosocial behaviors: nurturant, prosocial dominant, and responsible behaviors, and the contexts in which they occur. Nurturant behaviors were those wherein the target child was judged to be acting to meet the needs of another (e.g., giving food to another person, passing an object that was requested, helping another one dress); prosocial dominant behaviors were those wherein the child was judged to be attempting to change another person's behavior for the benefit of that other person (e.g., informing another child about norms, or controlling another person's behavior to prevent harm; Whiting, 1983; Whiting \& Edwards, 1988); responsible behaviors were those wherein the target child was performing a task that was "required, expected or preferred" by others (Whiting et al., 1966). Note that responsible behaviors were additionally defined as those that were not directly exhibited in relation to someone else (e.g., the child may be cooking, cleaning, washing clothes, tending the fire).

The contexts in which the prosocial behaviors occurred were originally coded into categories, which were based on the 11 contexts outlined by Munroe et al. (1982) in their time allocation study among children of four societies, one of which was the Gikuyu. Seven of the 11 settings were retained in their original form: chores, animal care, wage labor, garden labor, child rearing, visiting, and idleness. Three of the categorieshygiene, eating, and food preparation (for one's self), were subsumed under a single new category of self-care because of the infrequent observations in these settings, and their common focus on fulfilling the individual's needs. Additionally, coders had a somewhat difficult time differentiating these contexts. Similarly, the categories of chores, and garden and wage labor were combined because it was often difficult to differentiate when a child was performing tasks for the family's immediate needs (e.g., if they were gathering vegetables from the garden for family consumption) or for income (e.g., if they were gathering vegetables for selling in the market). Another category, play, was added, because of the large amount of time spent here. Of the original categories, "time spent in school" was eliminated, since only one observation was conducted during school time. This observation was excluded from analysis. The resulting five categories were childcare, play, idle/visiting, selfcare, and chores/labor.

For the coding procedure, four undergraduate research assistants were trained in classifying each behavior as being either non-prosocial, or falling under one of the three prosocial categories of nurturance, prosocial dominance, and responsible (work) behavior. After explaining the procedure, each research assistant was given a set of observations to code. When at least $90 \%$ agreement was achieved in coding the trial observations, research assistants were then given the observations to test for inter-rater reliability. Of 1,945 behaviors (45 observations), inter-rater agreement was $76 \%$. Inter-rater agreement was assessed by randomly selecting an average of 11 observations per coder and comparing this against the coding assigned by 
the researchers. Inter-rater agreement ranged from $73.4 \%$ to $82.6 \%(\kappa=.56)$. Coders were not made aware of the purpose of the study.

The observations were standardized for length of observation time. Using $15 \mathrm{~min}$ as a baseline (this was the most common length of the observation period), each observation was given a score based on how many 15-minutes increments were used up. Hence, an observation that was 30 minutes long was given 2 points, an observation $10 \mathrm{~min}$ long was given .67 points, and an observation 1 hour long was given 4 points. The observed frequencies were then divided by this value, resulting in an observed proportion score that reflected the number of prosocial acts per 15 minutes.

\section{Results}

Descriptive statistics for prosocial behaviors are summarized in Table 1. A series of preliminary one-way ANOVAs were conducted to examine gender differences in prosocial behaviors. Results of those analyses indicated no main or interaction effects for gender, so gender was excluded from the subsequent main analyses. A 3 (Age: 2-4 years., 4-6 years, 7-10 years) $\times 5$ (Context: play, labor/chores, childcare, idle/social, self care) $\times 3$ (Type prosocial behavior: nurturant, responsible, prosocial dominant) mixed factorial analysis of variance with context and type of prosocial behavior as within participants factors was conducted on scores for prosocial behaviors.

\section{Table 1}

Mean (and SD) incidence of prosocial behaviors for every 15min increment, presented separately by age group and type of prosocial behavior

\begin{tabular}{|c|c|c|c|c|c|}
\hline & Play & $\begin{array}{c}\text { Idle/ } \\
\text { social }\end{array}$ & $\begin{array}{r}\text { Child } \\
\text { care }\end{array}$ & $\begin{array}{c}\text { Labor/ } \\
\text { chores }\end{array}$ & Self-care \\
\hline \multicolumn{6}{|c|}{ Two-to three-year olds $(n=24)$} \\
\hline Nurturant & $.13(.32)^{\mathrm{ab}}$ & $.36(.60)^{a}$ & $.05(.16)^{\mathrm{b}}$ & $.06(.16)^{\mathrm{b}}$ & $.09(.41)^{\mathrm{b}}$ \\
\hline Responsible & $.03(.10)^{a b}$ & $.01(.05)^{\mathrm{ab}}$ & $.00(.00)^{\mathrm{b}}$ & $.06(.14)^{\mathrm{a}}$ & $.01(.04)^{\mathrm{b}}$ \\
\hline Prosocial dominant & $.06(.13)^{\mathrm{a}}$ & $.06(.21)^{\mathrm{a}}$ & $.00(.00)^{\mathrm{a}}$ & $.03(.10)^{\mathrm{a}}$ & $.00(.00)^{\mathrm{a}}$ \\
\hline Total & $.21(.32)^{a b}$ & $.44(.69)^{a}$ & $.05(.16) \mathrm{c}$ & $.15(.31)^{\mathrm{b}}$ & $.10(.41)^{\mathrm{bc}}$ \\
\hline \multicolumn{6}{|c|}{ Four-to six-year olds $(n=34)$} \\
\hline Nurturant & $.09(.22)^{\mathrm{a}}$ & $.08(.22)^{a}$ & $.12(.35)^{\mathrm{a}}$ & $.12(.26)^{\mathrm{a}}$ & $.05(.26)^{\mathrm{a}}$ \\
\hline Responsible & $.03(.10)^{b}$ & $.02(.07)^{\mathrm{b}}$ & $.09(.48)^{\mathrm{b}}$ & $.33(.54)^{\mathrm{a}}$ & $.02(.09)^{\mathrm{b}}$ \\
\hline Prosocial dominant & $.27(.57)^{a}$ & $.10(.35)^{\mathrm{ab}}$ & $.09(.24)^{\mathrm{ab}}$ & $.06(.14)^{\mathrm{ab}}$ & $.07(.22)^{\mathrm{b}}$ \\
\hline Total & $.38(.72)^{a b}$ & $.21(.42)^{\mathrm{b}}$ & $.30(.72)^{\mathrm{ab}}$ & $.51(.72)^{a}$ & $.13(.39)^{\mathrm{b}}$ \\
\hline \multicolumn{6}{|c|}{ Seven to nine-year olds $(n=31)$} \\
\hline Nurturant & $.17(.38)^{b}$ & $.07(.21)^{\mathrm{bc}}$ & $.42(.89)^{\mathrm{a}}$ & $.30(.66)^{a b}$ & $.02(.09)^{\mathrm{c}}$ \\
\hline Responsible & $.04(.18)^{b}$ & $.00(.00)^{b}$ & $.08(.37)^{\mathrm{b}}$ & $.78(1.18)^{\mathrm{a}}$ & $.01(.06)^{\mathrm{b}}$ \\
\hline Prosocial dominant & $.09(.20)^{\mathrm{ab}}$ & $.07(.21)^{\mathrm{b}}$ & $.27(.78)^{\mathrm{ab}}$ & $.37(.82)^{\mathrm{a}}$ & $.03(.18)^{\mathrm{b}}$ \\
\hline Total & $.29(.48)^{\mathrm{b}}$ & $.15(.39)^{b c}$ & $.77(1.76)^{\mathrm{ab}}$ & $1.45(1.83)^{\mathrm{a}}$ & $.06(.20)^{c}$ \\
\hline \multicolumn{6}{|l|}{ Total $(n=89)$} \\
\hline Nurturant & $13(.31)^{\mathrm{a}}$ & $.16(.38)^{\mathrm{a}}$ & $.21(.59)^{\mathrm{a}}$ & $.17(.44)^{\mathrm{a}}$ & $.05(.27)^{\mathrm{b}}$ \\
\hline Responsible & $.03(.13)^{b}$ & $.01(.05)^{\mathrm{b}}$ & $.06(.37)^{\mathrm{b}}$ & $.41(.82)^{a}$ & $.01(.07)^{b}$ \\
\hline Prosocial dominant & $.15(.39)^{\mathrm{a}}$ & $.08(.27)^{\mathrm{b}}$ & $.13(.49)^{\mathrm{ab}}$ & $.16(.51)^{a}$ & $.04(.17)^{\mathrm{c}}$ \\
\hline Total & $.37(.90)^{\mathrm{b}}$ & $.27(.63)^{\mathrm{b}}$ & $.42(1.62)^{\mathrm{b}}$ & $.90(1.95)^{\mathrm{a}}$ & $.11(.43)^{c}$ \\
\hline
\end{tabular}

${ }^{a-c}$ Means with the same superscripts are not significantly different across contexts within each age group and type of prosocial behavior. 
Main effects were found for context, $F(4,344)=6.68, \eta_{\mathrm{p}}^{2}=$ $.07, p<.001$, and age, $F(2,86)=5.98, \eta_{\mathrm{p}}^{2}=.12, p<.01$. These main effects were subsumed by a context $\times$ age, $F(8,344)=5.02, \eta_{\mathrm{p}}^{2}=$ $.11, p<.001$, and a context $\times$ type of prosocial behavior interaction, $F(8,688)=6.25, \eta_{p}^{2}=.07, p<.001$. These two-way interactions were further qualified by a three-way context $\times$ type of prosocial behavior $\times$ age interaction, $F(16,688)=2.24, \eta_{\mathrm{p}}^{2}=.05$, $p<.01$.

Context $\times$ type of prosocial behavior ANOVAS were conducted on prosocial behavior scores for each age group to decompose the three-way interaction. For 2- to 3-year olds, there were significant effects of context, $F(4,92)=3.82, \eta_{\mathrm{p}}^{2}=.14$, $p<.01$, type of prosocial behavior, $F(2,46)=6.38, \eta_{\mathrm{p}}^{2}=.22, p<$ .01 , as well as a context . type of behavior interaction, $F(8,184)$ $=3.17, \eta_{\mathrm{p}}^{2}=.12, p<.01$. Simple effects test of the context $\times$ type interaction revealed a significant effect of context for nurturant prosocial behaviors. LSD pair-wise comparisons of this simple effect showed that most nurturant acts were displayed in the idle/social context, followed by the play context $(p<.05)$, and then equally by childcare, labor/chores, and self-care. No significant context effects were found for the responsible and prosocial dominant behaviors for the youngest age group.

For the 4- to 6-year olds, there was a significant context $x$ type of behavior interaction, $F(8,264)=3.89, \eta_{\mathrm{p}}^{2}=.11, p<.01$. A simple effects test of this interaction revealed a significant effect of context for responsible behaviors, $F(4,132)=5.96, \eta_{\mathrm{p}}^{2}=$ $.15, p<.01$. LSD pair-wise comparisons showed that responsible behaviors for this age group occurred most often in the context of labor/chores $(p<.05)$, followed equally in all other contexts.
Finally, for the oldest age group of 7- to 10-year olds, there was a significant effect of context, $F(4,120)=7.82, \eta_{\mathrm{p}}^{2}=.21, p<$ .01 , subsumed by a context $\times$ type of behavior interaction, $F(8$, $240)=4.18, \eta_{\mathrm{p}}^{2}=.12, p<.01$. Simple effects test of this interaction revealed several significant context effects. For nurturant behaviors, there was a significant effect of context, $F(4,120)=$ $2.96, \eta_{\mathrm{p}}^{2}=.09, p<.05$. LSD pair-wise comparisons of this effect showed that most nurturant acts were shown in the context of childcare, followed by labor/chores $(p<.05)$, equally by play and idle/social, and finally by self-care contexts.

A significant effect of context was also found for responsible behaviors, $\left.F(4,120)=11.65, \eta_{\mathrm{p}}^{2}=.28, p<.01\right)$. LSD pair-wise comparisons of means showed that most responsible acts were shown in the context of labor/chores, followed by all other contexts $(p<.05)$.

A significant effect of context was also found for prosocial dominant acts, $\left.F(4,120)=2.85, \eta_{\mathrm{p}}^{2}=.09, p<.05\right)$. LSD pair-wise comparisons of this effect showed that most prosocial dominant acts were shown in the context of labor/chores, followed childcare and play, and then lastly by idle/social and self-care contexts $(p<.05)$. Results of all those pair-wise comparisons are summarized in Table 1.

\section{Discussion}

The purpose of the present study was to examine differences in age, gender, and the strength of context on types of children's prosocial behaviors as they occur in everyday settings. Differences in prosocial behaviors were found as a function of context and age. The findings suggest that specific contexts can elicit specific types of prosocial behaviors and emphasize age 
differences and mute or reduce gender differences. In general, the present findings were consistent with Snyder and Ickes' (1985) assertions that in contexts where there are strong situational demands, individual variability is muted and specific behaviors are elicited (see also, Whiting, 1980).

Context differences were found, generally consistent with the hypothesized degrees of strength in situational demands (see Snyder \& Ickes, 1985). These context differences varied for each specific type of prosocial behavior. Nurturant acts were displayed most often in the context of childcare; responsible acts were shown most in the context of labor/chores; and prosocial dominant behaviors were shown most in the contexts of childcare and labor/chores. There was a moderate number of prosocial acts in the play and idle/ social contexts, and the least number of prosocial acts during self-care. These patterns were evident in the two older age groups, while there was very little meaningful variability in the prosocial behaviors of the youngest age groups.

How does one explain context differences in the performance of specific types of prosocial behaviors? First, labor/chores was clearly the context in which most responsible prosocial behaviors were displayed. These findings were hypothesized because labor/chores is structured for the fulfillment of tasks. During labor/chores, children were expected to perform responsible behaviors, either because they were explicitly assigned the task, or because it was generally expected that they fulfill certain duties. Such responsible behaviors observed in this context included tending the fire, fetching water, cleaning the house, cooking, digging for food in the garden, and washing utensils, to name a few. Furthermore, unlike their peers in many Western industrialized nations, even young children in Ngecha were expected to participate in helping around the house. The present findings are consonant with research on rural Kenyan children who have been found to engage in less play than children from other world samples, or incorporate work with their play (Bloch \& Adler, 1994; Edwards, 2000).

Prosocial dominant behaviors were also most frequently observed in the labor/chores context. This may be attributed to the fact that many of the chores were done in the company of others. In Ngecha, mothers encouraged and supported older children exercising authority over younger ones in the service of getting work done and children cared for, and the age hierarchy was evident in observations. An example of the emergence of prosocial dominant behaviors during the context of labor/chores is seen in the following observation of a group of children doing garden labor:

\section{Example 1}

Rahab (male, age 7) asked Simeon (younger brother, 3) to move from near where he was digging, and Simeon complied. Rahab took the potatoes that Sarah (sister, 8) had gathered for him and put them on another spot, then resumed his digging. He told Salome (younger sister, 5) to pick up the potato vine and take it to put with the other ones. He told Simeon to move, and Simeon complied. He asked Simeon and Salome to help him by uprooting weeds, and they did. He asked Sarah to help him dig and told Salome to start collecting maize-stalks. He shouted and asked Salome to bring him a half calabash to put potatoes in. Salome did not obey, so he asked his mother to send Salome to bring him the calabash. Before the mother spoke, Salome took off and then returned carrying a small cooking pot, and Rahab told her to use it to collect potatoes. Sarah started help- 
ing Salome dig and Rahab, very pleased, told her "good, good Sarah."

Nurturant behaviors were displayed most frequently in the childcare context. As has been mentioned earlier, other investigators have suggested that contexts that place children in the company of younger peers, infants in particular, may elicit nurturant behaviors (Braten, 1996; Edwards, 1986; Hay \& Rheingold, 1983; Whiting \& Edwards, 1988). Because infants are relatively helpless and dependent, their presence may strongly elicit nurturance, and leave little room for variability in behaviors.

For the oldest age group, prosocial dominant behaviors were also quite prevalent in the childcare context (but not significantly different in frequency than the labor/chores context). A potential explanation for this is that in contrast to the dependent and relatively helpless infants, slightly older children (toddlers) are more mobile, though may still be dependent. Toddlers may tend to elicit more prosocial dominant behaviors because of their tendency to explore and move around (Whiting, 1983). As such, caregivers need to exert dominance to limit their movements in order to keep them safe, or to make them conform to socially expected standards and behaviors (Whiting \& Edwards, 1988).

These points contrasting nurturance to infants with prosocial dominance to a young child are illustrated in the following excerpts:

\section{Example 2}

Kimani (male, age 7) is carrying Ndungu (infant brother). His mother asked him to go outside and entertain the baby to make him stop crying, and Kimani obeyed after a short interval. He comforted the crying baby by patting him and asking him to get up. He sucked the baby's fingers and untied his sheet, getting him to sit on his lap. He wiped some feces from his knee and wiped the baby's bottom. He spread a small blanket on his lap for the baby to sit on.

\section{Example 3}

Naomi (female, age 6) told Amos (younger brother, 4) to get off the bed, and Amos complied. She told him to stop eating fat, and he did. She warned her other brother, Jomo (brother, 3) against standing on the bed frame so he wouldn't fall down, and Jomo got off. She told Amos to sit on a stool instead of stepping on it, and he agreed. Next in a reprimanding tone, she asked Amos why he was tying a string round Jomo's neck.

The first example illustrates the multiple needs of the infant, as well as the corresponding nurturant behaviors shown by the caregiver child. A context wherein a crying, helpless infant is present leaves little room for responses other than those nurturant in nature. The second example illustrates the dominant behaviors drawn from the caregiver child by the abilities and tendencies of the young children under her supervision. The pattern of findings, that high numbers of prosocial dominant behaviors emerged in childcare, was true for the oldest age group. Prosocial dominance is elicited most often by children younger than the actor, usually by a toddler (Whiting, 1983). Possibly, care of toddlers is relegated to older siblings, as they are more able to exert dominance and control the actions of a mobile and curious child. As such, it is possible that the age range for the current study is too low to capture the high incidence of prosocial dominant acts that would be more emergent in slightly older children.

Both nurturant and prosocial dominant behaviors emerged frequently in the play and idle/social contexts. Both these con- 
texts are relatively unstructured and usually have no predetermined goal that is related directly to prosocial acts; indeed, sometimes aggression can result from play behaviors. However, studies with Western children suggest that depending on the specific type of play, certain behaviors may be elicited that include cooperation and other positive acts (Finlinson, Austin, \& Pfister, 2000). Additionally, these trends may be due to crossage playgroups that children in this community often have. As has been mentioned earlier, being in the presence of younger peers may tend to elicit nurturant behaviors when the other child is an infant, and dominance when the other child is a toddler (Whiting \& Edwards, 1988). Ethnographic accounts of the Gikuyu and other African children also suggest that play is traditionally a context in which important skills and social roles are learned, even above formal education (Bloch \& Adler, 1994; Kenyatta, 1966), and children often incorporate their work in the context of play (Edwards, 2000). Taken together, these observations might provide an explanation as to why such high incidences of nurturant and prosocial dominant behaviors were found in these contexts.

In addition to the context and type effects on prosocial behaviors, there were some main effects of age on prosocial behaviors. For example, age differences were found, such that older children generally showed more prosocial acts as compared to their younger peers. This is consistent with previous studies that have shown increasing prosocial tendencies with age in Western, industrialized groups (Eisenberg, 1992; for review, Eisenberg \& Fabes, 1998) and world samples (Whiting $\&$ Edwards, 1973, 1988). There are at least two possible reasons for those age differences. First, researchers have suggested that age differences may be attributed to various factors such as advances in socio-cognitive abilities, including changes in assessing others' emotions, needs, and perspectives, or changes in information processing capabilities; changes in emotional development, such as the ability to empathize and sympathize with others; and lastly, increasing physical abilities to carry out helpful acts (Eisenberg, 1992; Knight, Bohlmeyer, Schneider, and Harris, 1993; Radke-Yarrow et al., 1983). Second, the present age differences might reflect age differences in how mothers assign children to the various contexts. Past research indicates that with increased age, children in East Africa and other rural settings where children are a regular part of the family work force, spend more time doing chores and childcare and less time idle (Apoko, 1967; Munroe et al., 1982). Unfortunately, the nature of the present data set did not allow for direct examination of the relative amounts of time spent by children in each setting, making it difficult to choose between these explanations.

Interestingly, there were no gender differences in prosocial behaviors. Existing literature is mixed with regards to the existence of gender differences, but when differences have been observed, they seem to favor girls, at least among older children and adolescents (Eisenberg \& Fabes, 1998).

Some researchers have proposed that whether gender differences are found is sometimes a function of how prosocial behaviors were defined in the study, and alternatively, gender differences seem to vary across different measures (Eisenberg \& Fabes, 1998). In the current examination, the behaviors were defined by the action rather than the intention. As such, regardless of whether the behavior was compliance to an order, or whether it was self-motivated, the act was coded as prosocial as long as it was directed at benefiting others. In the contexts of childcare and labor/chores, participation in the setting is sometimes not a choice but an expected or assigned respon- 
sibility. Thus, consistent with Snyder and Ickes' (1985) notions, gender differences might have been suppressed by the strong demands of the situation. Finally, the relatively small size of the sample and the uneven sampling of girls and boys could have resulted in insufficient statistical power to detect gender differences.

Both boy and girl Ngecha children spent a great deal of time together in settings overseen by elder women (mothers, grandmothers) prior to adolescence and initiation ceremonies. Much household and subsistence work needed to be done in these settings-contexts where adults recruited child assistance. In the present study, children were assigned tasks (e.g., chores, childcare), which almost necessitated the performance of prosocial behaviors, regardless of individual preference. Likewise, Harkness and Super (1985) found, for example, that gender segregation did not emerge in Kokwet children of Western Kenya as early as it has been observed in U.S. samples (Jacklin \& Maccoby, 1978). The children in the Kenyan samples were frequently assigned tasks and helping roles, and frequently put together in mixed-age groups of siblings and close relatives. These contexts serve to organize the children's behaviors and steer them in particular ways.

There were some limitations to the present study. First, the naturalistic design of the study limits one's ability to discern direction of causality effects. Second, equal distribution of age groups was not possible because of the study design. And third, the unique cultural and historical context limits generalizations to present day society. Despite these limitations, developmental scholars have noted the inherent advantages of naturalistic observation research in rarely studied populations to cross-validate the functional equivalence of existing developmental models in ecologically valid settings.
The present study contributes to the existing literature in a number of ways. First, the study supports recent theorists' suggestions for the need to examine the development and correlates of specific types of prosocial behaviors (see e.g., Carlo \& Randall, 2001). Second, the research provides some support for Snyder and Ickes' (1985) contention that strong environments (relative to weak environments) might elicit and account for individual differences in social behaviors. This notion can be applied to developmental studies and can further our understanding of children's prosocial development. Third, the study illustrates the potential for cultural research utilizing naturalistic methods to uncover developmental processes (such as the impact of the immediate settings) that are unique to specific cultural and historical contexts.

The present findings have important implications for educators and parents. Because few American children contribute very much today to the work of their families or communities, their lives may be low on experiences that can contribute most readily to learning and practicing prosocial behavior. In prior centuries, certainly, children participated more often in social and economic family work units where they assisted people whose lives they shared (Rogoff, 2003; Whiting \& Edwards, 1988). These are the kinds of environments that most readily elicited prosocial behaviors in Ngecha children and where consequences were built in so that children could see the direct results of what they did and were satisfied immediately (e.g., the food got cooked, there was water to drink, the baby stopped crying). American toddlers have been observed to eagerly imitate and seek to participate in the household work of family adults (Rheingold, 1982), but little theoretical or practical attention has been devoted to the emergence of this kind of prosocial behavior. 
Likewise, preschool educators realize that young children are often glad and consider it a privilege to help adults in early childhood settings (Gonzalez-Mena, 2005), but the cultural stress on play and child-centered activity as the most appropriate types of learning situations for children result in little curricular focus on mixed-age interaction or on the kinds of lessons that Maria Montessori (1912/1964) called "practical life." Presenting children with more opportunities to practice helping behaviors by assigning prosocial duties and responsibilities in educational settings might foster prosocial behavioral tendencies in children. As Carlo (2005) noted, settings that encourage children to practice prosocial behaviors might become the "training grounds" for promoting prosocial tendencies. Thus, by assigning prosocial behavior duties and responsibilities, educators can create strong environments that pull for strong prosocial norms and mores.

\section{Acknowledgement}

We are indebted to the late Beatrice Whiting, Professor Emeritus Harvard University, for the use of the Ngecha behavior observations, and acknowledge the research project conducted under the auspices of the Child Development Research Unit, Bureau of Educational Research, Nairobi University, Kenya. We thank the families of Ngecha and the research collaborators and apprentices who participated in the collection of the behavior observations. Maria de Guzman was partially supported by a Summer Research Fellowship from the University of Nebraska-Lincoln. Carolyn Edwards was partially supported by the Institute for Agricultural and Natural Resources, University of Nebraska-Lincoln, Journal Series 13632. Gustavo Carlo was supported by an award from the John Templeton Foundation and the American Psychological Association.

\section{References}

Apoko, A. (1967). At home in the village: Growing up Achioli. In L. K. Fox (Ed.), East African childhood: Three versions (pp. 45 -78). New York: Oxford University Press.

Batson, C. D. (1998). Altruism and prosocial behavior. In D. T. Gilbert S. T. Fiske \& G. Lindzey (Eds.). Handbook of social psychology, Vol. 2 (4th ed.) (pp. 282 -316). Boston, MA: McGraw-Hill.

Berman, P. W., \& Goodman, V. (1984). Age and sex differences in children's responses to babies: Effects of adult's caretaking requests and instructions. Child Development, 55, 1071 -1077.

Bloch, M. N., \& Adler, S. M. (1994). African children's play and the emergence of the sexual division of labor. In J. L. Roopnarine, J. E. Johnson \& F. H. Hooper (Eds.), Children's play in diverse cultures (pp. 148-178). New York: State University of New York Press.

Braten, S. (1996). When toddlers provide care: Infants' companion space. Childhood, 3, 449-465.

Cagnolo, C. (1933). The Akikuyu, their customs, traditions and folklore. Nyeri, Kenya: Mission Printing School (V.M. Pick, Trans.).

Carlo, G. (2005). Care-based and altruistically-based morality. In M. Killen \& J. G. Smetana (Eds.), Handbook of moral development. Mahwah, NJ: Lawrence Erlbaum Associates.

Carlo, G., Fabes, R., Laible, D., \& Kupanoff, K. (1999). Early adolescence and prosocial/moral behavior II: The role of social and contextual processes. Journal of Early Adolescence, 19, 133 -148.

Carlo, G., Knight, G. P., Eisenberg, N., \& Rotenberg, K. J. (1991). Cognitive processes and prosocial behaviors among children: The role of affective attributions and reconciliations. Developmental Psychology, 27, 456-461. 
Carlo, G., \& Randall, B. (2001). Are all prosocial behaviors equal? A socioecological developmental conception of prosocial behavior. In F. Columbus (Ed.), Advances in psychology research, Vol. II (pp. 151 -170). Huntington, NY: Nova Science Publishers.

Cox, F. M. (1977). Aging in a changing village society: A Kenyan experience. Washington, D.C.: International Federation on Ageing.

Edwards, C. P. (1986). Another style of competence: The caregiving child. In A. Fogel \& G. F. Melson (Eds.), Origins of nurturance: Developmental, biological and cultural perspectives on caregiving (pp. 95-111). Hillsdale, NJ: Lawrence Erlbaum Associates.

Edwards, C. P. (1993). Behavioral sex differences in children of diverse cultures: The case of nurturance to infants. In M. E. Pereira \& L. A. Fairbanks (Eds.), Juvenile primates: Life history, development, and behavior (pp. 327-338). New York: Oxford University Press.

Edwards, C. P. (2000). Children's play in cross-cultural perspective: A new look at the Six Culture Study. Cross Cultural Research, 34, 318 -338 .

Edwards, C. P. \& Whiting, B. B. (1980). Differential socialization of girls and boys in light of cross-cultural research. In C. Super \& S. Harkness (Eds.), Anthropological perspectives on child development (pp. 45-58). San Francisco: Jossey-Bass.

Edwards, C. P., \& Whiting, B. B. (1993). "Mother, older sibling, and me": The overlapping roles of caregivers and companions in the social world of two-to three-year-olds in Ngecha, Kenya. In K. MacDonald (Ed.), Parent-child play: Descriptions and implications (pp. 305-328). Albany, NY: State University of New York Press.

Edwards, C. P. \& Whiting, B. B. (Eds.). (2004). Ngecha: A Kenyan village in a time of rapid social change (pp. 701-778). Lincoln: University of Nebraska Press.

Eisenberg, N. (1992). The caring child. Cambridge, MA: Harvard University Press.
Eisenberg, N., \& Fabes, R. A. (1998). Prosocial development. In W. Damon \& N. Eisenberg (Eds.). Handbook of child psychology: Social and personality development, Vol. 4 (5th ed.) (pp. 701-778). New York: Wiley.

Ember, C. (1973). Feminine task assignment and the social behavior of boys. Ethos, 1, $424-439$.

Farver, J. M. (1999). Activity setting analysis: A model for examining the role of culture in development. In A. Göncü (Ed.), Children's engagement in the world: Sociocultural perspectives (pp. 99-127). New York: Cambridge University Press.

Finlinson, A. R., Austin, A. M. B., \& Pfister, R. (2000). Cooperative games and children's positive behaviors. Early Child Development and Care, 164, $29-40$.

Fogel, A., \& Melson, G. F. (1986). Origins of nurturance: Developmental, biological, and cultural perspectives on caregiving. Hillsdale, NJ: Erlbaum.

Gonzalez-Mena, J. (2005). Foundations of early childhood education: Teaching children in a diverse society. New York: McGraw Hill.

Grusec, J. E., Goodnow, J. J., \& Cohen, L. (1997). Household work and the development of children's concern for others. Developmental Psychology, 32, 999-1000.

Harkness, S., \& Super, C. M. (1985). The cultural context of gender segregation in children's peer groups. Child Development, 56, 219224.

Hay, D. F., \& Rheingold, H. L. (1983). The early appearance of some valued social behaviors. In H. Beilin \& D. L. Bridgeman (Eds.), Developmental psychology series. The nature of prosocial development: Interdisciplinary theories and strategies (pp. 79-94). New York: Academic Press. 
Jacklin, C. N., \& Maccoby, E. E. (1978). Social behavior at thirty-three months in same-sex and mixed-sex dyads. Child Development, 49, 557-569.

Kenyatta, J. (1966). Facing Mount Kenya: The tribal life of the Gikuyu. New York: Random House.

Knappert, J. (1987). East Africa; Kenya, Tanzania and Uganda. New Delhi, India: Vikas Publishing.

Knight, G. P., Bohlmeyer, E. M., Schneider, H., \& Harris, J. D. (1993). Age differences in sharing as a function of task-specific cognitive prerequisites: Time estimation ability and a fixed-duration sharing task. British Journal of Developmental Psychology, 11, 143-158.

Larson, R. W., \& Verma, S. (1999). How children and adolescents spend time across the world: Work, play, and developmental opportunities. Psychological Bulletin, 125, 701-736.

Leacock, E. (1976). At play in African villages. In J. S. Bruner A. Jolly \& K. Sylva (Eds.), Play: Its role in development and evolution (pp. 45 -473). New York: Basic Books.

Leakey, L. S. B. (1977). The Southern Kikuyu before 1903. London: Academic Press.

Leiderman, P. H., \& Leiderman, G. F. (1977). Economic change and infant care in an East African agricultural community. In P. H. Leiderman S. R. Tulkin \& A. Rosenfeld (Eds.), Culture and infancy (pp. 405-438). New York: Academic Press.

Lloyd, B., \& Smith, C. (1986). The effects of age and gender on social behaviour in very young children. British Journal of Social Psychology, 26, $33-41$.

Miller, P. A., Kozou, J., \& Davis, A. C. (2001). Social influence, empathy, and prosocial behavior in cross-cultural perspective. In $\mathrm{W}$. Wosinka, R. B. Cialdini, D. W. Barrett, \& J. Reykowski (Eds.), The practice of social influence in multiple cultures (pp. 63-78). Mahwah, NJ: Lawrence Erlbaum Associates.
Montessori, M. (1912/1964). The Montessori method. New York: Schocken.

Munroe, R. H., Munroe, R. L., \& Shimmin, H. S. (1984). Children's work in four cultures: Determinants and consequences. American Anthropologist, 86, 369-379.

Munroe, R. L., \& Munroe, R. H. (1977). Cooperation and competition among East African and American children. Journal of Social Psychology, 101, 145-146.

Munroe, R. L., Munroe, R. H., Michelson, C., Koel, A., Bolton, R., \& Bolton, C. (1982). Time allocation in four societies. Ethnology, 22, $355-370$.

Nsamenang, A. B. (1992). Human development in cultural context: A third world perspective. Cross-cultural research and methodology, Vol. 16. Newbury Park, CA: Sage Publications.

Radke-Yarrow, M., \& Zahn-Waxler, C. (1976). Dimensions and correlates of prosocial behavior in young children. Child Development, 47, 118-125.

Radke-Yarrow, M., Zahn-Waxler, C., \& Chapman, M. (1983). Children's prosocial dispositions and behavior. In P. H. Mussen (Ed.), Carmichael's manual of child psychology, Vol. 4 (pp. 469 -546). New York: Wiley.

Reid, P. T., Tate, C. S., \& Berman, P. W. (1989). Preschool children's self-presentations in situations with infants: Effects of sex and race. Child Development, 60, $710-714$.

Rheingold, H. L. (1982). Little children's participation in the work of adults: A nascent prosocial behavior. Child Development, 53, 114125.

Rogoff, B. (2003). The cultural nature of human development. New York: Oxford University Press. 
Rogoff, B., Newcombe, N., Fox, N., \& Ellis, S. (1980). Transitions in children's roles and capabilities. International Journal of Psychology, $15,181-200$.

Rogoff, B., Sellers, M. J., Pirrotta, S., Fox, N., \& White, S. H. (1975). Age of assignment of roles and responsibilities to children. A cross-cultural survey. Human Development, 18, 353 -369.

Snyder, M., \& Ickes, W. (1985). Personality and social behavior. In G. Lindzey \& E. Aronson (Eds.), Handbook of social psychology, (3rd ed.). Research methods, Vol. 2 (pp. 883 -947). New York: Random House.

Super, C. M. (1990). The cultural regulation of infant and child activities. In B. Schurch \& N. S. Scrimshaw (Eds.), Activity, energy expenditure and energy requirements of infants and children (pp. 321333). Lausanne: Nestle.

Super, C. M., \& Harkness, S. (1986). The developmental niche: A conceptualization at the interface of child and culture. International Journal of Behavioral Development, 9, 545 -569.

Super, C. M., \& Harkness, S. (1999). The environment as culture in developmental research. In S. L. Friedman \& T. D. Wachs (Eds.), Measuring environment across the life span: Emerging methods and concepts (pp. 279 -323). Washington, DC: American Psychological Association.

Tietjen, A. M. (1986). Prosocial reasoning among children and adults in a Papua New Guinea society. Developmental Psychology, 6, 861868.

Tudge, J., Hogan, D., Lee, S., Tammeveski, P., Meltsas, M., Kulakova, N., et al. (1999). Cultural heterogeneity: Parental values and beliefs and their preschoolers activities in the United States, South Korea, Russia, and Estonia. In A. Göncü (Eds.), Children's engagement in the world. Sociocultural perspectives (pp. 62 -96). Cambridge: Cambridge University Press.
Weisner, T. (2002). Ecocultural understanding of children's developmental pathways. Human Development, 45(4), 275-281.

Weisner, T. S. (1996). The 5 to 7 transition as an ecocultural project. In A. Sameroff \& M. Haith (Eds.), The five to seven year shift: The age of reason and responsibility (pp. 295-306). Chicago: University of Chicago Press.

Weisner, T. S., \& Gallimore, R. (1977). My brother's keeper: Child and sibling caretaking. Current Anthropology, 18, 169-190.

Wenger, M., (1976). Child-toddler interaction in an East African community. Unpublished qualifying paper, Harvard Graduate School of Education, Cambridge Mass.

Whiting, B. B. (1980). Culture and social behavior: A model for the development of social behavior. Ethos, 8, 95-115.

Whiting, B. B. (1983). The genesis of prosocial behavior. In D. L. Bridgeman (Ed.), The nature of prosocial development (pp. 221 -242). New York: Academic.

Whiting, B. B., (2003). Ngecha, Kenya, Behavior Observations. Collected by Beatrice Whiting and Research Collaborators in 19681972. Edited by Carolyn Pope Edwards. Compiled by Maria Rosario Tretasco de Guzman in collaboration with Melissa Kobus, Nicole Miller, Jennifer Tuel, Melissa Lynn Freyer, Lanette Christensen, Jessica Ranjbar, Lacy M. Gacke, Emily Eisenhauer, Carolyn Connelly, Natalie Kovtun, Wenli Liu, Andrew Kovtun, and Megan Husset. New Haven, CT: Human Relations Area Files Press, CD Rom format.

Whiting, B. B., \& Edwards, C. P. (1973). A cross-cultural analysis of sex differences in the behavior of children aged 3-11. Journal of Social Psychology, 91, 171-188.

Whiting, B. B., \& Edwards, C. P. (1988). Children of different worlds: The formation of social behavior. Cambridge, MA: Harvard University Press. 
Whiting, B. B., \& Whiting, J. W. M. (1971). Task assignment and personality: A consideration of the effects of herding on boys. In $\mathrm{W}$. Lambert \& R. Weisbrod (Eds.), Comparative perspectives on social psychology (pp. 33-45). Boston, MA: Little Brown.

Whiting, B. B., \& Whiting, J. W. M. (1975). Children of six cultures: A psycho-cultural analysis. Cambridge, MA: Harvard University Press.

Whiting, J. W. M., Child, I. L., Lambert, W. W., Fischer, A. M., Fischer, J. L., Nydegger, C., et al. (1966). Six cultures series: Field guide for a study of socialization, Vol. 1. NY: John Wiley and Sons.

Worthman, C. M., \& Whiting, J. W. M. (1987). Social change in adolescent sexual behavior, mate selection, and premarital pregnancy rates in a Kikuyu community. Ethos, 15, 145-165.

Zahn-Waxler, C., Friedman, S. L., \& Cummings, E. M. (1983). Children's emotions and behaviors in response to infants' cries. Child Development, 54, 1522 -1528. 